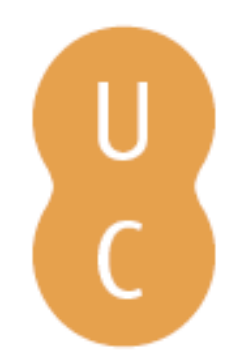

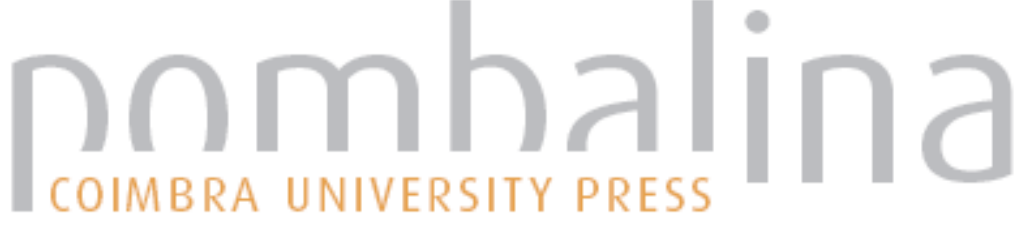

\section{Pugna verborum: alegoria e parateatralidade na Corte Enperial}

Autor(es): $\quad$ Pereira, Paulo Alexandre

Publicado por: Imprensa da Universidade de Coimbra

URL

persistente:

URI:http://hdl.handle.net/10316.2/30842

DOI:

DOI:http://dx.doi.org/10.14195/978-989-26-0218-9_2

Accessed : $\quad$ 26-Apr-2023 14:15:50

A navegação consulta e descarregamento dos títulos inseridos nas Bibliotecas Digitais UC Digitalis, UC Pombalina e UC Impactum, pressupõem a aceitação plena e sem reservas dos Termos e Condições de Uso destas Bibliotecas Digitais, disponíveis em https://digitalis.uc.pt/pt-pt/termos.

Conforme exposto nos referidos Termos e Condições de Uso, o descarregamento de títulos de acesso restrito requer uma licença válida de autorização devendo o utilizador aceder ao(s) documento(s) a partir de um endereço de IP da instituição detentora da supramencionada licença.

Ao utilizador é apenas permitido o descarregamento para uso pessoal, pelo que o emprego do(s) título(s) descarregado(s) para outro fim, designadamente comercial, carece de autorização do respetivo autor ou editor da obra.

Na medida em que todas as obras da UC Digitalis se encontram protegidas pelo Código do Direito de Autor e Direitos Conexos e demais legislação aplicável, toda a cópia, parcial ou total, deste documento, nos casos em que é legalmente admitida, deverá conter ou fazer-se acompanhar por este aviso. 
Marta Teixeira Anacleto e Elsa Branco

Coordenação

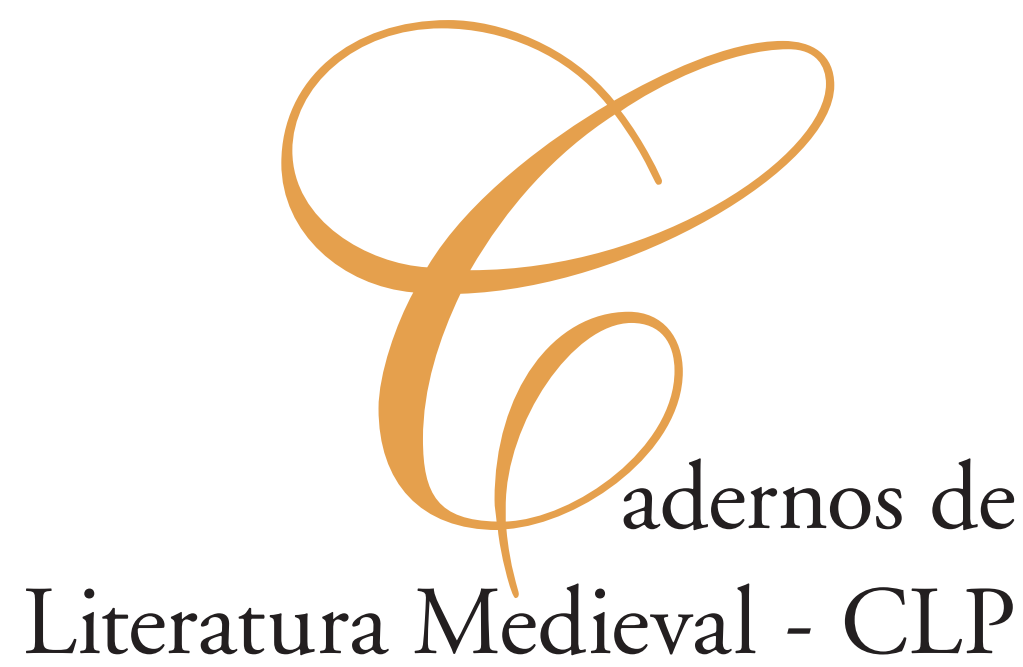

A Prosa Didáctica Medieval 


\section{Paulo Alexandre Pereira \\ Universidade de Aveiro}

\section{PUGNA VERBORUM: ALEGORIA E PARATEATRALIDADE NA CORTE ENPERIAL}

\section{1.}

A Corte Enperial é uma obra de autor desconhecido, provavelmente um clérigo ou monge ${ }^{1}$, transmitida por um único manuscrito apógrafo, conservado na Biblioteca Pública Municipal do Porto, datável de meados do século XV. Não dissentindo da proposta de Cruz Pontes, o autor que incontestavelmente mais rendosa atenção crítica tem dispensado ao texto, o seu mais recente editor, que, baseando-se em dados de natureza histórico-linguística, faz remontar a sua composição à centúria anterior ${ }^{2}$. Embora o unicum de que dispomos inclua a menção de haver pertencido a Afonso Vasco de Calvos, morador na cidade do Porto, ainda vivo em 1454, sabe-se que um exemplar constava do rol dos livros de D. Duarte e que, nos primeiros anos do século seguinte, um outro, hoje desaparecido, terá sido doado, por disposição testamentária da infanta D. Beatriz, aos monges franciscanos do Convento de Santo António em Beja.

Trata-se de um texto integrável na escassa tradição da literatura controversista medieval em língua portuguesa e terá sido a originalidade deste testemunho das relações inter-religiosas mantidas em solo peninsular, a par da invulgar erudição evidenciada pelo autor no domínio das fontes arabo-islâmicas, que, mais recentemente, levaram Adel Sidarius a formular a hipótese de tratar-se a obra de tradução portuguesa de um original catalão, provavelmente recolha de textos ou thesaurus de testimonia com

${ }^{1}$ Mário Martins, "Corte Imperial", in Alegorias, Simbolos e Exemplos Morais da Literatura Medieval Portuguesa. Lisboa: Edições Brotéria, 1980, p. 209. Cf. «E quem escreveu estas páginas conhecia a Bíblia por dentro e por fora. Devia ser clérigo ou monge».

2 Adelino de Almeida Calado (ed.), Corte Enperial. Aveiro: Universidade de Aveiro, 2000, p. XI-XIII. 
finalidades apostólicas de missionação cristã, organizada nos meios dominicanos catalães próximos de Raimundo Martî̉ ${ }^{3}$. Obra original ou tradução, o certo é que ela parece constituir "o primeiro importante texto filosófico e teológico redigido em português» ${ }^{4}$ e se, como salienta Adelino de Almeida Calado, «nos lembrarmos de que um rei e um mercador se irmanaram no interesse por ela» ${ }^{5}$, certamente se justifica que à Corte Enperial regressemos com renovados pretextos de inquirição.

A questão da justa medida da originalidade do texto é explicitamente formulada pelo autor no prólogo, que, depois reivindicar a tradução «das autoridades da Santa Scriptura com declarações e exposiçoões de doutores e per razões evidentes e neçesarias e dizeres de baroōes sabedores declaradas de latim em linguagem purtugues», adverte, logo na etapa de praeparatio, num gesto tópico de humildade auto-apresentativa corrente na prosa de feição doutrinária, que «eu, pecador, confiando começo este livro, nom como autor e achador das cousas em elle contheudas, mais como sinprez ajuntador dellas em hũu vellume ${ }^{6}$. Ora, o inventário sistemático das fontes da obra, levado a cabo a partir do esforço pioneiro do erudito jesuíta Abílio Martins, passando pelas posteriores investigaçóes de Cruz Pontes e, sobretudo no tocante às fontes árabes, pelas recentes aduções de Adel Sidarius, vieram, com efeito, confirmar a relevância das tarefas de tradução e compilação na composição da obra. A colação das principais fontes aproveitadas pelo autor-compilador - Nicolau de Lyra, Raimundo Lúlio, Isidoro de Sevilha, o De Vetula pseudo-ovidiano, os textos corânicos, entre

3 Adel Sidarius, «Le Livro da Corte Enperial entre l'apologétique lulienne et l'expansion catalane au XIVe siècle», in Horácio Santiago-Otero (ed.), Diálogo Filosófico-Religioso entre Cristianismo, Judaismo e Islamismo durante la Edad Media en la Peninsula Ibérica. Turnhout: Brepols, p. 147-148. Relativamente à questão da autoria, Cruz Pontes sugere, em função da proximidade das datas de composição, das afinidades doutrinárias e da comum inclinação alegórica, ser o autor da Corte Enperial o mesmo do Boosco Deleitoso. Cf. J. M. da Cruz Pontes, "Raimundo Lulo - na polémica medieval religiosa do "Livro da Corte Imperial"», in Ernildo Stein (org.), A Cidade de Deus e a Cidade dos Homens de Agostinho a Vico. Festschrift para Luis Alberto de Boni. Porto Alegre: EDIPUCRS, 2004, p. 681-695. Comentando a hipótese avançada por A. Sidarius, nota que admiti-la implica «aceitar que o tradutor português teria alterado o original que utilizava e substituíra a expressão originária "traduzido do latim para o catalão" pela afirmação de que as suas argumentaçôes eram "declaradas de latim em linguagem português"». Cf. ibid., p. 695.

${ }^{4}$ J. M. da Cruz Pontes, "Corte Enperial (Livro da)», in Biblos. Enciclopédia Verbo das Literaturas de Lingua Portuguesa. Vol. 1. Lisboa: Verbo, 1995, p. 1308.

${ }^{5}$ Adelino de Almeida Calado (ed.), Corte Enperial., p. V.

${ }^{6}$ Ibid., p. 11. Todas as referências à Corte Enperial remetem para a edição interpretativa de Adelino de Almeida Calado e serão, a partir deste momento, integradas no corpo do texto. 
outras - com o texto da Corte Enperial permitiu a Cruz Pontes concluir que, nessa adição crítica de discursos, "o autor (...) não se prendeu servilmente aos textos que aproveitou, não só porque os seleccionou e ordenou a seu modo, como porque também alterou, ora comentando e alargando, ora resumindo e sintetizando, as exposições doutrinais de que se serviu» ${ }^{7}$. Assim se explica a «incerta forma literária de alguns capítulos» ${ }^{8}$, em que a reflexão polémico-teológica em torno dos artigos da fé cristã ou o escrutínio de minúcias exegéticas aparecem coligados com o visualismo evocativo de uma «justa religiosa» 9 figurada sob espécie alegórica.

E, assim, se, por um lado, as apreciações críticas da Corte Enperial têm, sem excepção, reconhecido a sua débil originalidade teológico-doutrinária na tematização da «rivalidade dos monoteísmos» ${ }^{10}$, nem por isso deixam de resgatar o texto em função do que Cruz Pontes lapidarmente considerou ser a sua «arquitectura poética original» ${ }^{11}$, aludindo à moldura teatralizante que ameniza a secura apologética do texto e que parece, até prova que o desminta, poder atribuir-se à inventiva do autor.

\section{2.}

Às flutuantes classificações tipológicas apostas à Corte Enperial não é alheia a problemática reconstituição do público histórico visado pelo texto e, portanto, a dificuldade em determinar o seu ambíguo estatuto pragmático. Se, como parece inegável, se reproduz, em larga medida, o argumentário convencional e a estrutura dialogada que legitimamente o aparentam à literatura de controvérsia religiosa adversus judaeus, adversus gentiles e adversus mauros ${ }^{12}$, nele se rastreiam quer uma indeclinável intenção apologética, que se salda na exaltação exclusivista do cristianismo como fides única - assim dirimindo qualquer dilema ecuménico -, quer a elocução abstracta

7 J. M. da Cruz Pontes, Estudo para uma edição crítica da Corte Enperial. Coimbra: Universidade de Coimbra, 1957, p. 185.

8 Ibid., p. 185.

${ }^{9}$ Mário Martins, «A polémica religiosa nalguns códices de Alcobaça». Brotéria, no 42 (1946), p. 241.

10 Recupero a formulação de R. Fletcher, The Barbarian Conversion. From Paganism to Christianity. Berkeley: University of California Press, 1999, p. 285.

${ }^{11}$ J. M. da Cruz Pontes, «Originalidade literária da Corte Enperial». Diário Ilustrado, 2 de Março de 1957, s. p.

${ }^{12}$ Cf. Maria de Lourdes S. Ganho, «A perspectiva ética na obra anónima 'Corte Enperial'», in Marcos Roberto N. Costa, Luis A. de Boni (orgs.), A Ética Medieval Face aos Desafios da Contemporaneidade. Porto Alegre: EPIPUCRS, 2004, p. 663. 
lógico-demonstrativa próxima do tratado teológico, quer a orientação pastoral da cura animarum que parece transplantada de um catecismo prático ${ }^{13}$. Esta textualidade compósita permitirá justificar alguma vacilação classificativa, tendo a obra sido, alternadamente, descrita como "compêndio de teologia» 14 , "tratado de uma teologia prática, combativa, a exemplo da teologia de ação praticada por Raimundo Lúlio» ${ }^{15}$, «diálogo teológico-filosófico» ${ }^{16}$, «vasta disputa escolástica e de sabor ecuménico» ${ }^{17}$ ou «manual para os homens ocupados com a conversão dos infiéis» ${ }^{18}$.

Compreende-se este embaraço taxonómico. Através do breve confronto com duas outras obras de polémica religiosa, em língua portuguesa, que apresentam indesmentíveis afinidades com a Corte Enperial, poder-se-á dar conta da heterogeneidade de modelos textuais convencionalmente integrados na categoria lábil da literatura controversista. Refiro-me ao Tratado Theologico ou Livro da crença cristã, versão portuguesa, realizada ainda durante o reinado de D. Dinis, do Libro de las tres creencias, atribuído a Alfonso de Valladolid (1270-1249), rabino da cidade de Burgos convertido ao cristianismo, e ao Diálogo de Robim e do Teólogo, texto anónimo derivado do Livro das Confissóes de Martim Peres. O Tratado Theologico, à semelhança da Corte Enperial, e de modo estruturalmente mais rigoroso, obedece à ordem expositiva dos catorze artigos do Símbolo apostólico, no propósito de provar que «em na sinagoga e na mezquita se encobre a verdade e demostra a mentira, pois vos veedes destes dous caminhos qual he o milhor. Ca pello caminho da verdade, vay homem ao parayso e pello caminho

${ }^{13}$ Mário Santiago de Carvalho considera, aliás, a relevância da dimensão pastoral como um dos traços singulares do desenvolvimento da filosofia em Portugal, entre os séculos XIII e $\mathrm{XV}$ : «A aplicação dos conhecimentos tradicionais de interpretação escriturística à homilética para o grande público pode ser contada como um dos traços específicos da cultura portuguesa que assim progride num sentido demograficamente horizontal cada vez mais vasto». Cf. "Conspecto do desenvolvimento da filosofia em Portugal (séculos XIII-XV)». Revista Española de Filosofia Medieval, no 4 (1997), p. 137.

${ }^{14}$ J. M. da Cruz Pontes, «Raimundo Lulo - na polémica medieval religiosa do "Livro da Corte Imperial”", p. 689.

${ }^{15}$ Michel Sleiman, «Fé, razão e diferenças na Corte enperial», in Ângela Vaz Leão, Vanda de Oliveira Bittencourt (orgs.), Anais do IV Encontro Internacional de Estudos Medievais. Belo Horizonte: PUC Minas, 2003, p. 670.

${ }^{16}$ Maria de Lourdes S. Ganho, "A perspectiva ética na obra anónima 'Corte Enperial'", p. 665.

${ }_{17}$ Mário Martins, "O Livro da Corte Imperial», in As Grandes Polémicas Portuguesas. Lisboa: Verbo, 1964, p. 33.

${ }^{18}$ Michel Sleiman, «As reais cortes da Corte enperial», in Lênia Márcia de Medeiros Mongelli (coord.), A Literatura Doutrinária na Corte de Avis. São Paulo: Martins Fontes, 2001, p. 44. 
da mentira, vay o homem ao inferno» ${ }^{19}$. Como na Corte Enperial, o autor socorre-se tanto da argumentação bíblica como das similitudines extraídas do universo natural, provavelmente por inspiração corânica, uma vez que, antecipando a pertinácia de judeus e mouros, considerar crucial a probatio exaustiva dos artigos da fé cristã «com muitas provas e boas da ley» e «pellas naturas todas» ${ }^{20}$. Embora pontualmente amparada por analogias, a árida exposição didáctico-apologética constitui, como aliás seria de esperar, a tonalidade retórica dominante do tratado. Nesse sentido, converte-se a especulação doutrinária em indissimulada coacção ideológica e repudia-se inapelavelmente a apostasia, numa clara demonstração de judeofobia de que apenas encontramos vestígios residuais nessa factícia "cultura de tolerância» ${ }^{21}$ - já considerada «fruto da experiência portuguesa de irenismo e convivencialidade entre as três religiōes do Livro» ${ }^{22}$ - que subjaz à Corte Enperial. Embora prevaleça, portanto, uma dicção abstracta, monopólio exclusivo do tratadista catequizador, que propende para a dissolução da plurivocalicade dos contendores, nem por isso o autor deixa de revelar-se consciente de que a sua é uma enunciação com destinatário:

Faço vos pergunta judeus, quem foy aqueste que assy foi ferido de taaes feridas per todallas partes do corpo. Se dizedes que foy este propheta Isayas, nom acharedes em nehũa scriptura que elle assy fosse ferido, nem estas pallavras nom lhas podedes apropriar nem a outro nem que suas sejam, senom ao Filho de Deus que segundo a humanidade quis seer ferido e chagado por nos seermos salvos $(\ldots) .^{23}$

No Diálogo de Robim e do Teólogo, que Mário Martins certeiramente descreveu como um «catecismo liliputiano» 24 , a relação magisterial-discipular entre «hũũ pphilosafo

19 José Antunes, A cultura erudita portuguesa nos séculos XIII e XIV (Juristas e Teólogos). Coimbra: Faculdade de Letras, 1995, pp. 702-703.

20 Ibid., pp. 684-685.

${ }^{21}$ María Rosa Menocal, The Ornament of the World: How Muslims, Jews and Christians Created a Culture of Tolerance in Medieval Spain. Boston: Little, Brown \& Company, 2002.

22 Maria Cândida Monteiro Pacheco, «Corte Imperial», in Giulia Lanciani, Giuseppe Tavani (orgs.), Dicionário da Literatura Medieval Galega e Portuguesa. Lisboa: Caminho, 1993, p. 170.

23 José Antunes, A cultura erudita portuguesa nos séculos XIII e XIV (Juristas e Teólogos), p. 724 .

${ }^{24}$ Mário Martins, «O 'Diálogo de Robim e do Teólogo’. Brotéria, no 53 (1951), p. 272. 
jentil que oue nome Robim e deseiaua mujto desser christaao» e "hũũ grande meestre ẽ tooligia» ${ }^{25}$ assenta na mimetização de um pouco convincente efeito de interlocução. $\mathrm{Na}$ realidade, a despeito da estrutura responsória de superfície, dificilmente se pode considerá-lo um verdadeiro diálogo, constituindo antes uma espécie de texto transicional, em que um catecismo se finge altercatio teológica. Os pedidos de esclarecimento endereçados ao mestre constituem meros pretextos para estadear doutrina formalizada e nunca ocasião de confronto inter-religioso, dando razão a Mário Martins quando observou que «o anónimo autor do Diálogo de Robim e do Téologo tinha, diante de si, o Livro das Confissões, suprimia os comentários e passagens capazes de supressão, metendo em diálogo seco, de perguntas e respostas, a substância essencial da doutrina de Martin Pérez» ${ }^{26}$.

$\mathrm{Na}$ Corte Enperial, a transcontextualização que acompanha a metamorfose do tratado de apologética cristã em disputatio alegórica afectará medularmente os códigos técnico-compositivos e, em decorrência, a força ilocutória do texto. António José Saraiva sugeriu que «A Corte Imperial [se] apresenta (...) como um compendium dirigido a um público amplo, fora do grémio clerical, como o mostra o facto de estar escrito em língua portuguesa e o de recorrer a todos os processos literários capazes de aliciar e prender o leitor» ${ }^{27}$. A ser assim, a intentio operis - a missionação evangelizadora - é inseparável do trabalho retórico-literário por ela agenciado, o que, bem vistas as coisas, significa que, efectivamente, «a intenção apologética não matou o artista que era o autor português deste livro medieval» ${ }^{28}$. Cruz Pontes vai mais longe, adiantando que a obra «poderia (...) destinar-se a preparar os missionários que embarcavam com os marinheiros nas viagens iniciadas em Quatrocentos» e que, à semelhança do que se sabe ter ocorrido com exemplares da tradução portuguesa da Vita Christi, «talvez algum códice do Livro da Corte Enperial tivesse seguido nos navios» ${ }^{29}$.

25 Henry Hare Carter (ed.), Paleographical Edition and Study of the Language of a Portion of Codex Alcobacensis 200. Philadelphia: University of Pennsylvania, 1938, p. 37.

26 Mário Martins, "O "Diálogo de Robim e do Teólogo"», p. 274.

27 António José Saraiva, O crepúsculo da Idade Média em Portugal. Lisboa: Gradiva, 1988, p. 143.

28 J. M. da Cruz Pontes, «Teatralidade da Corte Enperial». Diário Ilustrado, 7 de Maio de 1957, s.p.

${ }^{29}$ J. M. da Cruz Pontes, «Raimundo Lulo, o Colégio de Miramar e Portugal». Itinerarium, no 96-97 (1977), p. 209-210; idem, "Corte Enperial (Livro da)», in Biblos. Enciclopédia Verbo das Literaturas de Lingua Portuguesa. Vol. 1. Lisboa: Verbo, p. 1310. 
A proclamada originalidade literária da Corte Enperial parece, por conseguinte, aliar-se a uma retórica instrumental da conversão que explora as possibilidades da encenação alegórica como expediente didáctico. Na verdade, parece ser o efeito teatral de doutrina dramatizada que, com sintomática persistência, é convocado a propósito da valoração literária do texto. Descrevendo a obra como «teatro de grandiosidade helénica» ${ }^{30}$, «ópera (...) com o seu quê de pastoral» 31 , «teatralização de uma controvérsia religiosa» ${ }^{32}$, «dramatização de [uma] polémica» ${ }^{33}$, ou como "fantasia teatral» ${ }^{34}$ de singular «aparato cénico» 35 , em "cujo palco os actores reagem, manifestam júbilo, cantam louvores e expressam alteraçōes fisionómicas de arguto registo pelo relator» ${ }^{36}$, as aproximações críticas do texto têm reincidido, com entusiasmo porventura excessivo, no leitmotiv crítico da endoutrinação sob espécie dramática. O que, em todo o caso, parece certo é que uma ética da disputatio convive, no texto, com uma inequívoca vontade performativa, inscrevendo a sua prioritária vocação didáctico-catequética num espaço intermédio entre textualidade e teatralidade ${ }^{37}$.

\section{3.}

A tauoada inicial e as divisōes capitulares presentes no manuscrito da Corte Enperial, eficazes processos remissivos, permitem supor o funcionamento do texto como uma espécie de promptuarium argumentativo, pelo arranjo lógico da doutrina teológico-especulativa seguramente ditado pela necessidade de localização expedita dos meios de prova. O programa de escrita consignado pelo autor-compilador no prólogo, uma

30 J. M. da Cruz Pontes, Estudo para uma edição crítica da Corte Enperial, p. 188.

${ }^{31}$ Mário Martins, "A música religiosa na "Corte Imperial”", in Estudos de Literatura Medieval. Braga: Livraria Cruz, 1956, p. 417.

32 Maria Cândida Monteiro Pacheco, "Corte Imperial», p. 169.

33 Maria de Lourdes S. Ganho, "A perspectiva ética na obra anónima 'Corte Enperial'", p. 672.

34 J. M. da Cruz Pontes, «Raimundo Lulo - na polémica medieval religiosa do "Livro da Corte Imperial"», p. 691.

35 J. M. da Cruz Pontes, «Corte Enperial (Livro da)», p. 1310.

36 J. M. da Cruz Pontes, "Apostilas para a edição crítica do Livro da Corte Enperial». Humanitas, no 58 (2006), p. 233.

37 Rebeca Sanmartín Bastida, Teatralidad y Textualidad en el Arcipreste de Talavera. London: Queen Mary, University of London/Department of Hispanic Studies, 2003, p. 16. 
vez dilucidado o alcance figurativo do título e a prevalência do regime alegórico consubstanciado nas cortes celestiais, insiste na pluralidade caucionadora das fontes:

(...) he composto este livro, que he chamado Corte inperial, e tal nome lhe he posto porque, asy como na corte do rey e do emperador ou doutro alto príncipe sooem a seer trautados os grandes negoçios e os altos feitos e as árduas questóes determinadas, asy este livro trauta de grandes cousas e de muy altas questoões, asy como da essência de Deus e da Trindade e da encarnaçom divinal e doutras materias proveitosas pera conhecer e entender o Senhor Deus segundo o poder da franqueza humanal, provando todo per autoridades da Santa Scriptura com declarações e exposiçoões de doutores e per razões evidentes e neçesarias e dizeres de baroões sabedores (...). (p. 9)

O quadro áulico, que pressupõe a curialização metafórica das matérias da fé, subserve o modelo hermenêutico da interpretação figural, instaurando a cenografia alegórica do locus amoenus onde decorrerão as cortes convocadas pelo Celestial Imperador, bem como a expressiva prosopografia crística ${ }^{38}$ - que, como acontece com os litigantes gentios, judeus ou muçulmanos, redundará em inevitável etopeia -, apresentadas com notável minúcia descritiva em capítulo subsequente. Importa salientar que esta topografia simbólica é regulada por leis estritas de proxémia: o «real barom glorioso» é ladeado pelas duas rainhas da Igreja Triunfante e da Igreja Militante e, num plano significativamente afastado, permanecem as «companhas que estavam em aquellas reaaes cortes» (p. 15), as "gentes de desvayradas seitas e de desvayradas creenças que estavam em aquelle grande canpo» (p. 16), delineando-se assim uma geografia simbólica da multiconfessionalidade. Trata-se, com efeito, de uma litigação entre diferentes, porquanto a disputa se trava entre a alegoria personificante da Igreja Militante, reificada na sages rainha católica, e diferentes tipos emblemáticos do paganismo (filósofos) e dos monoteísmos judaico (rabinos) e islâmico (alfaquis).

38 Como informa Cruz Pontes, o retrato de Cristo segue a fonte latina da Epistola Lentuli: «Trata-se do aproveitamento de um retrato fantasiado da imagem física de Jesus, provavelmente de origem grega mas redigido em latim e divulgado pela Europa em fins do século XIII ou princípios do seguinte, inserido em um apócrifo posto a circular como sendo Carta de Lêntulo, ou Públio Lêntulo, dito 'governador de Jerusalém', endereçada 'ao Senado e ao povo romano', concluindo que Cristo era, como predizia o salmo XLV, 3, 'speciosus inter filios hominum'». A mesma epístola foi inserida no prólogo da Vita Christi, de Ludolfo de Saxónia. Cf. J. M. da Cruz Pontes, "Apostilas para a edição crítica do Livro da Corte Enperial», pp. 243-244. 
Contracenam, pois, sem que o facto gere qualquer perplexidade, personagens com desigual consistência ontológica. Aliás, a acumulação de traços distintivos de gentios, judeus e mouros - nomes próprios, pormenores fisionómicos, reacçôes mimo-gestuais e emotivas, sinais de acolhimento variável dos dogmas apresentados - terá que entender-se não tanto como descriptio individualizante ou estratégia de encarecimento de qualquer das confissões congregadas neste "vasto concílio ecuménico» ${ }^{39}$, mas antes como reenvio metonímico para os distintos sistemas doxológicos em confronto e notação intencional da oscilante receptividade dos seus sequazes à verdade cristã:

Quando a gloriosa reinha acabou as razōes quy ditas som, logo o fillosopho gintill falou altamente, dizendo: "Senhora muy sabedor reinha, eu creeo e entendo todo aquelo quy vós dito avedes do Senhor Deus e da sua Trindade, e as vossas razões são neçesarias e verdaedeiras”. E, tanto quy ell esto dise, logo todos os gentiis quy aly estavam outorgarom com elle. Mais dos judeus muy poucos teverom aquela razom nem creerom nem quiserom entender, mais ficarom em sua perfiia. Ca o reby dos judeus confesou a Trindade, mas poucos teverom com elle. Outrosy dos mouros muy mais poucos entenderom nem crerom as suas razões e achegaron.se a ella. (p. 117)

A Corte Enperial reedita, assim, compaginando-o com uma sintaxe dialógico-disputativa, o catálogo de topoi constantes da literatura de polémica religiosa, por meio da «ampliação escriturística e racional do Credo» 40 e da fundamentação dos dogmas católicos: a estrutura trina e una da essência de Deus, a Sua revelação à humanidade na figura de Cristo encarnado, a Paixão, a Ressurreição e o Juízo Final, a Eucaristia. Instigada por um infatigável furor demonstrandi, a Igreja Militante dá voz e corpo a um projecto argumentativo que, desde logo, se consuma em opçóes declaradas de dispositio que a levam a, em nome da conveniência de ordem demonstrativa, diferir ou reiterar argumentos. Estilemas de sentido catafórico, como «segundo se mostrará adiante mais claramente e mais conpridamente quando falarmus da Triindade de Deus» (p. 30), dizem tanto da premeditação retórica deste discurso, como da sua adaptação às circunstâncias particulares de um auditório heteróclito,

${ }^{39}$ A expressão é utilizada por Mário Martins em «A polémica religiosa nalguns códices de Alcobaça». Brotéria, no 42 (1946), p. 242.

${ }^{40}$ Mário Martins, "O Livro da Corte Imperial», in As Grandes Polémicas Portuguesas, p. 31. 
insinuando uma rectificação in fieri da táctica oratória. A interpretação dos sinais paralinguísticos recebidos do auditório, os parciais triunfos demonstrativos da oradora ou, inversamente, a inconciliadora obstinação do antagonista podem justificar um desvio estratégico do rumo retórico previsto:

Depois que a católica rainha dise estas razões, levantou-se hũu filosopho d.antre o povoo dos jentiis e dise em esta guisa: "Rainha senhor, praza.vos de me ouvirdes, ca eu nom quero falar contra vós em perfia nem com argumentos em contrairo, senom por perguntar e saber tirar alghũas duvidas do meu coraçom, ca as vosas razões asaz me parecem boõas e fremosas, mais muito me espanto que, pois Jhesu Christo foy aquele homem que era Deus, parece-me que nom devera Deus ssofrer per nẽhũa guisa que ele fose prove e despreçado e morto em este mundo, mais devera-o fazer rico e honrado e conhecido e amado de todolos homẽẽs". Respondeu a católica rainha: "Filosopho amigo, a my praz de vos escuitar de melhor talente que estes judeus em que ha muita perfia. E porem daquy em diante nom entendo de provar minhas tençốes pelas Escripturas, pois que as eles tam mal querem entender, pero, se me alghũas razões fezerem contra a verdade, responder.lhes.ey o melhor que eu poder. Ora, filosopho amigo, respondo aa vosa razom. (p. 187)

A probatio concretiza-se pela aliança reciprocamente esclarecedora de fides e ratio, traduzindo-se na convocação abonatória das escrituras autenticas e das razoóes neçesarias. Estas últimas configuram provas racionais dos dogmas da fé com valor apodíctico, claramente tributárias do modelo polémico-racionalista das rationes necessariae de Raimundo Lúlio ${ }^{41}$. A dívida em relação ao Doctor Illuminatus estende-se ainda à referência às dignitates de Deus, à recreaçom ${ }^{42}$, ou aos chamados correlativos lulianos

${ }^{41}$ Refere Vincent Serverat que «dans les oeuvres qu'il adresse aux infidèles, Ramon Lull aura tendence à placer três haut le degré de nécéssité pour ses preuves sur la Trinité, l'incarnation $\mathrm{du}$ Verbe, etc. Par contre, devant un public de théologiens et d'universitaires, non plus aux marges de la chrétienté mais à Paris, l'auteur devra mettre en valeur les droits de la foi et rabaisser d'autant la validité de ses rationes necessarias». Cf. Vincet Serverat, L'Être et la Joie. La philosophie de Ramon Llull dans le "Le Libre d'amic e amat». Greifswald: Reineke-Verlag, 1993, p. 234.

42 «Como ergo asy seya quy o homem, pello pecado, se desviou daquela fim e perfeiçom naturall pera que foy feito, ergo Deus pode reduzer o homem aaquela fim primeira, e a tall reduzimento chamamos recreaçom», p. 142. 
que ecoam em grande parte da argumentação aduzida pela Igreja Militante ${ }^{43}$. Uma vez que a finalidade apologética da rainha católica esbarra quer com a incoincidência de cânones de textos sagrados, quer com insanáveis desacordos na interpretação de passos escriturísticos, as razões necessárias apresentam-se como modalidades de evidência, permitindo-lhe estatuir uma ordem argumentativa de força crescente. Deste modo, em bom magistério retórico, adequam-se os meios de prova ao auditório: "pera eu provar que Deus he, nom faz mester trager prova per a Santa Scriptura porque aquelles que neguam aver hy Deus nom recebem nem creem a Santa Scriptura e porem conpre outras provas per outras razoões neçesarias que entendo de trazer» (p. 17).

Embora a rainha católica detenha autoridade simbólica e ascendente elocutório incontestados sobre o público refractário à fé cristã - dilatando sem constrangimentos as suas intervençôes, orquestrando o multilóquio dos contendores e não se abstendo de adoptar um tom assertivo ou mesmo admonitório ${ }^{44}$-, o seu ânimo erístico não prescinde de protocolos de cortesia que, por vezes, parecem já evocativos da civilitas dos colóquios humanistas, numa insinuação de abertura ecuménica que, de imediato, é contraditada pela intransigência exclusivista da argumentação e pela liminar indisponibilidade para firmar qualquer compromisso doutrinário com as fés minoritárias. Por outro lado, a ponderação dos acordos prévios que caracterizam o auditório, bem como a preocupação de o fazer admitir as premissas da argumentação, destinam-se a acautelar a veiculação eficaz do ensinamento dogmático ${ }^{45}$, mesmo se a ensinança nem sempre se vem a materializar na ambicionada conversão.

43 Ricardo da Costa, «Muçulmanos e Cristãos no diálogo luliano», Anales del Seminario de Historia de la Filosofia (UCM), no 19 (2002), pp. 67-96.

44 «Muyto se maravilharom os filósofos e os rebis dos judeus e os alfaquis dos mouros das palavras da gloriosa reynha. E fallarom antre sy que maneyra terriam em razoar contra a crença da Trindade dos christaãos e concordarom que falasem por todos os philosophos jentiis, ficando aguardado aos outros contradizer em aquello que lhe conprise. E a gloriosa reynha lhes dise que se sofresem, ca ainda ella queria mais razoar», p. 66.

45 «'Rainha senhor', dise o filosopho gentil, 'bem avedes provada vosa teençom per aqueles que crêem os artigoos da fe que ditos avedes. Ora vos praza de falardes em outras cousas de vosa fe, se ainda som por dizer'. 'Filosopho amigo', dise a rainha católica, 'ainda hy ha outros artiigoos da fe christãa de cousas que ainda som por viir, e o primeiro he que Jhesu Christo, Deus e homem verdadeiro, ha.de julgar os vivos e os mortos em a fim do mundo. Mais, pera nós esto provarmos, queremos ante provar duas cousas: a primeira he que a geeraçom dos homens avera fim, a segunda he que todolos homẽs am.de resurgir com seus corpos. Estas duas cousas provadas, entom provaremos que o Senhor Jhesu Christo ha.de julgar os homens'", pp. 202-203. 
A ars disputandi da Igreja Militante assenta, em larga medida, na exploração de argumentos quase lógicos, isto é, dotados de uma força demonstrativa reminiscente da dos raciocínios lógico-formais. Terá sido este peculiar uso retórico, mais do logos que do pathos, que levou Mário Martins a afirmar que «através das páginas da Corte Imperial, transparece, sobretudo, um raciocinador de formação escolástica» ${ }^{46}$. A infrequência dos argumentos ad hominem revela que são as crenças falaciosas hipostasiadas nos interlocutores o verdadeiro móbil da disputa. Como observa Ch. Perelman, a argumentação filosófica - com a qual teologia polémica e especulativa apresenta indisfarçáveis afinidades - visa um auditório universal e deve, portanto, evitar o uso de argumentos apenas válidos para grupos particulares e dirigir-se, pelo contrário, ad humanitatem $^{47}$. A confutatio desenvolvida pela rainha implica, não obstante, jogar habilmente no terreno do adversário, prognosticando os seus contra-argumentos ou, por exemplo, minando a sua credibilidade por meio da técnica argumentativa da retorsão que consiste em «retomar o argumento do adversário mostrando que na verdade este é aplicável contra ele mesmo» ${ }^{48}$, de modo que, na expressiva imagem da rainha católica, «hũu clavo seja revitado e abatido com outro clavo»:

E porem se vós, dom reby, arguides que Jhesu de Nazaret nom foy verdadeiro Misias per razom dos pecados daquelas molheres de que ele deçende, per esa mesma razom e per mais forte aquele Misias que vós atendedes, que ha.de deçender de David, nom sera verdadeiro Misias porque David, de que ele ha.de deçender, foy envolto em tantos pecados e tam graves. (p. 183)

O profuso arsenal argumentativo patenteado nas extensas réplicas da rainha - que inclui a definição e a enumeração, a ilustração, a similitudo e a metáfora, a analogia e o exemplum - testemunha tanto a sua perícia dialéctica, como um indefectível zelo de instrução pastoral dos disputantes, sobretudo no que respeita à inteligibilidade dos mistérios da fé junto de um auditório com uma assimétrica preparação teológica.

46 Mário Martins, «A polémica religiosa nalguns códices de Alcobaça», p. 248.

47 Chaïm Perelman, Lucie Olbrechts-Tyteca, Tratado da Argumentação. Lisboa: Instituto Piaget, 2006, p. 123.

48 Olivier Reboul, Introdução à Retórica. São Paulo: Martins Fontes, 1998, p. 169. 
Trata-se, pois, de impor uma "polissemia controlada» ${ }^{49}$ em face da polifonia de escrituras e do impasse exegético. Investe-se, assim, numa pedagogia associativa que privilegia o esclarecimento dogmático através da comparação das verdades da fé com palpabilia concretizantes, como acontece na dilatada analogia entre a eternidade da alma e a arte do ferreiro:

E, se Deus nom fose, a alma do homem, que he a primeira e principal enteçom, nom acalçaria sua fim nem sua perfeiçom pera que foy feita, ca morreria o homem asy como hũu cam. E, depois sua morte, nom seria nẽhũa cousa, bem asy das outras cousas artefiçiaes, asy como na arte do ferreiro, em que o martello he pera seer o cravo. E o cravo, pera aver o ferreiro dinheiros e os dinheiros som pera aver per elles o pam e o pam he pera viver o ferreiro. E asy a vida do ferreiro he a fim e a primeira entençom pera que som todas estas cousas e cada hũa dellas acalça sua fim pera que foy feita ca o martello acalça sua fim em no cravo e o cravo em no dinheiro e o dinheiro em ho pam e o pam em a vida do ferreiro. (p. 25)

Pregadora sagaz, não é de estranhar que a rainha católica manifeste uma constante preocupação em adaptar as técnicas argumentativas aos distintos núcleos confessionais que intenta persuadir: se o gentio sem fé é tabula rasa permeável a qualquer demonstração de autoridade, apenas o uso concertado desta com a prova por razões necessárias parece poder abalar a contumácia dos rabinos entrincheirados na sua inexpugnável cultura teológica ${ }^{50}$. Os filhos de Mafoma, por seu turno, parecem particularmente seduzidos pela persuasão pelo exemplum e, no seu caso, a rainha não hesita em recorrer o argumento do terceiro excluído: “"Ainda mais quero provar”, dise a rainha católica,

49 Rita de Cássia Boeira Campos, O próximo como o "outro": Cristianismo e Judaísmo na Corte Imperial (Portugal, Século XV). Porto Alegre: UFRGS, 2005, p. 33.

50 Como sublinha Maria José Ferro Tavares, «Santo Agostinho opunha à "ingenuidade dos Gentios" a "perversidade dos Judeus", mas não os excluía da salvação nem da eleição de Deus, pois constituíam o primeiro povo eleito. Segundo este doutor da Igreja, os judeus faziam parte da salvação definida por Deus para a humanidade, sendo uma das paredes da pedra angular que é Cristo, ou seja uma parede era constituída pelos Judeus, a outra pelos Gentios que iriam formar a comunidade cristã. Eles permaneceriam afastados, até se reunirem na pedra angular». Cf. Maria José Ferro Tavares, "A construção de um estereótipo: o judeu no Mediterrâneo ocidental e o seu reflexo na arte (séculos XII a XVI)», in Maria Filomena Lopes de Barros, José Hinojosa Montalvo (eds.), Minorias étnico-religiosas na Peninsula Ibérica. Periodos medieval e moderno. Lisboa: Colibri-CIDEHUS, p. 21. 
"que a ley de Mafomede he falsa e a ley dos christaãos he verdadeira” (p. 227). Por outro lado, o seu discurso não consegue escamotear a falácia lógica que consiste «em querer provar a verdade da lei de Cristo com o Alcorão e simultaneamente demonstrar a falsidade da lei de Maomé» 51 .

O ethos da oradora católica deflui, por conseguinte, tanto da sua superior tarefa de envangelização, reivindicando-se porta-voz dos dogmas da única fé verdadeira, como da enunciação de uma ética da çiencia de desputar sobre as cousas spirituaaes e divinaaes fundada na superioridade da doxa em relação à episteme. Assim parece poder entender-se a advertência que serve de antelóquio ao debate:

Porem, se vós queredes aparelhar morada em vossos coraçoóes da ciençia spritual, conpre.vos que vos desenbarguedes da coydaçom de todollos pecados e dos coydados deste presente segre. Ca nom pode seer que a alma ocupada em nos cuydados mundanaaes mereça o dom e graça da verdadeira sabedoria nem seja geerador dos sentidos sprituaaes. Outrosy seer nom pode que aquelle que, com propósito de gaançar louvor dos hom es, aprende ou estuda ou lee, que mereça o dom e graça da verdadeira çiençia. E nom pode seer que o homem guaanhe çiençia nem inteligençia das cousas sprituaaes e divinaaes se ouver a sua alma cuja, nem pode aver çiençia de desputar e de muito razoar avondosamenre e fermosamente. Mais outra cousa he aver muitas palavras e apostas, e outra cousa he entrar em nas veas e em nos meolos dos dizeres çelestriaes e contenplar com ho olho mui puro do coraçom os sacramentos e os segredos profundos, altos e escondidos, a qual cousa homem nom pode guaanhar per doutrina humanal nem per ensinança sagral, mais per alumiamento do Spritu Santo, tam solamente per linpeza da mente. (p. 16-17)

Nesta «afirmação dos valores da simplicidade e da humildade da razão, perante os dogmas da fé» 52 confluem reflexão teológica e consciência metalinguística. Com efeito, é na lúcida percepção da falência do entendimento e da linguagem humanos na revelação dos «segredos profundos, altos e escondidos» do Verbo divino - «ca as palavras do homem não são perfeitas pera falar propriamente de Deus porque os

${ }^{51}$ Maria Celeste Sousa Silva, Corte Enperial. Porto: Faculdade de Letras, 2005, p. 81.

52 Pedro Calafate (ed.), «O Livro da Corte Imperial», in História do Pensamento Filosófico Português. Lisboa: Caminho, 1999, p. 535. 
homens nom som perfeitos pera entender nem pera recontar as cousas que som en Deus» (p. 11) - que se faz entroncar a dupla defesa do contemptus mundi e do contemptus sui. Prerrogativa indeclinável de penetração na profundidade mistérica, a limpeza do coração impõe uma "destemporalização perceptiva» ${ }^{53}$, que postula o primado da vidência e da audição espirituais, exortando o fiel a ver com «ho olho mui puro do coraçom» e a escutar «com o coraçom e com as orelhas pera ouvir as cousas da phe christãa» (p. 42). A propósito das provas da Trindade, a rainha advoga, glosando o credo ut intelligam anselmiano, a filosofia fundada na crença, tornando, portanto, a inteligibilidade da transcendência irredutível a um estreito naturalismo racionalista:

Porque vós, filosopho gentil, sodes em hũu acordo contra a creença da Triindade com os alfaquis dos mouros e com o reby dos judeus, porem eu a todos quero responder per hũuas razoões a esto que me perguntades, como quer que vos declarey já esto que me ora demandades. Mais ainda vos quero mais provar esto que me perguntades, pero que nom queredes creer. E porem nom o podedes entender. E asy diz o profeta Isayas: 'Se non creredes non entenderedes'. (p. 91)

A flagrante improficuidade da arte da eloquência na decifração do verdadeiro sentido espiritual terá como corolário a condenação da fatuidade da disputatio escolástica quando entendida como um fim em si própria, loquacidade pedante e inconsequente ou mero duelo verbal. A expressão pugna verborum, fórmula de S. Paulo, presente na Primeira Epístola a Timóteo ${ }^{54}$, retomada por S. Bernardo e outros autores monásticos, traduzia, como refere J. Leclercq, a desqualificação teológica da compulsão disputativa e do prazer colhido nas subtilezas da arguição. Os que a ela se

53 Mário Martins, Introdução histórica à vidência do tempo e da morte. Braga: Livraria Cruz, 1969 , p. 25. Cf. as seguintes palavras do autor: «Livres da visão das sombras, os cegos levantam-se com mais facilidade à contemplação do que não é deste mundo. Os surdos escutam melhor a palavra interior, com a orelha do coraço, elevados em êxtase Os que têm o olfacto pouco apurado procuram os odores sobrenaturais, com que o Senhor chama as almas», p. 28.

54 I Tim., VI, 3-6: «Se alguém ensinar uma outra doutrina e não concorda com as sãs palavras de nosso Senhor Jesus Cristo e com a doutrina conforme a piedade, é porque é soberbo, nada entende, é um doente à procura de controvérsias e discussôes de palavras. Daí nascem inveja, brigas, blasfémias, más suposições, altercações intermináveis entre homens de espírito corrupto e desprovidos de verdade, supondo que a piedade é fonte de lucro». 
entregavam incorriam em intemperança intelectual, desrespeitando a palavra de Deus e despromovendo-a ao estatuto de uma qualquer arte liberal ou mecânica ${ }^{55}$. Se a disputatio, como desporto dialéctico, podia representar um antídoto seguro contra a acédia nascida na solitária ruminação especulativa, o seu abuso com propósitos fruitivos podia instigar à soberba e alienar o crente da transcendência.

A sumária teoria hermenêutica reconstituível a partir das palavras da rainha católica, em sintonia com a qual «toda a doutrina he declarada e provada per hũa de duas guisas» - por "prinçipios evidentes e manifestos» ou "per testimunho devinal» (p. 168) -, torna imperativa a interpretação per figuram, esperando-se, por seu intermédio, compensar as limitaçôes da elocução humana na nomeação das coisas de Deus. Falar «em fegura e em semelhança» (p. 175) constitui, pois, uma apologia da obliquidade metafórica que permite designar o que, de outro modo, seria inapreensível:

E porem, como quer que as nosas pallavras nom sejam perfeitas, nom he de ter mentres ao desfaliçimento das palavras, mais aaquello que per ellas entendemus significar e demostrar, ca nós teemos que nom pode nẽhũu falar propriamente de Deus porque os homẽs nom som perfeitos pera entender aquellas cousas que som em Deus nem as pallavras dos homens som perfeitas pera as recontar nem dizer. (p. 107-108)

Por isso, tão frequentemente o debate entre a gloriosa rainha e os contendores, sobretudo os judeus, se centra no modus recipiendi das escrituras e, em particular, na ditologia letra-espírito. Na realidade, estas aporias interpretativas implicam que de parte a parte sejam esgrimidos intermináveis argumentos filológicos que, em regra, expõem as insuficiências do rigorismo literal e estéril da exegese judaica. Em

55 Jean Leclercq, Initiation aux auteurs monastiques du Moyen Âge. L'amour des lettres \& le désir de Dieu. Paris: Les Éditions du Cerf, 1956, p. 192. Acrescenta ainda o autor: «Or la doctrine sacrée doit rester aute chose et plus qu'une discipline libérale. A plus forte raison ne peut-on la réduire à n'être qu'un métier. Pourtant, au témoignage d'un scolastique tel que Pierre le Chantre, il arrivait qu'on fît de la théologie une technique parmie les autres. Et contre cette sorte de dégradation, de profanation des mystères de Dieu, réagissaient les moines: ils craignaient que l'on ne s'arrêtât aux procédés de la dispute, qui risquait de devenir intéressante pour elle-même, où chacun pouvait mettre en valeur sa personnalité, à force d'apporter des arguments nouveaux», p. 193. 
consequência, o debate fixa-se em minúcias tradutológicas, abundantemente ilustradas pela dissensão a propósito da unidade e da pluralidade da divindade que se faz entroncar na polinomásia veterotestamentária de Deus (nome tetragramático, Elohim, Adonai). Este meticuloso exame do traslado da sacra pagina demonstra que, na realidade, a controvérsia judaico-cristã radica num conflito de interpretações fundado em inconciliáveis divergências de tradução e de exegese. Mesmo sustentando que «hũu paso escuro da Santa Escriptura nom se deve expoer senom per outro paso mais claro desa mesma Escriptura» (p. 129), a rainha católica será forçada, em face da cegueira hermenêutica dos judeus ${ }^{56}$, a abdicar da via que se prova infecunda da demonstração através da auctoritas dos textos sagrados e a enveredar por argumentos filosóficos necessários e evidentes.

\section{4.}

A encenação da palavra doutrinária conduz-nos, outra vez ainda, à qualificação metafórica da Corte Enperial como teatro e do seu autor como «dramaturgo ao divino» 57 . Num notável estudo onde reflecte sobre as fronteiras da teatralidade na Idade Média, Alan Deyermond salienta a existência de diferenças indiscutíveis entre manifestações parateatrais e obras de teatro stricto sensu, elencando aqueles que julga constituírem

56 Como refere Daniel J. Lasker, "Christians criticized Jewish interpretations of the Hebrew Bible and rabbinic literature, insisting that this literature provided proof of the truth of their own religion if understood correctly; Jews, on their part, regarded the Hebrew Bible and the New Testament as sources for the invalidation, not the justification, of the majority religion. Although exegesis generally followed theology rather than shaping it, nevertheless, the bulk of the debate, as measured by the extant literature, ostensibly was devoted to matters of hermeneutics». Cf. Daniel J. Lasker, "Imagination and Intellect in the Medieval Jewish Philosophical Polemics against Christianity», in Maria Cândida Pacheco, José F. Meirinhos (eds.), Intellect et Imagination dans la Philosophie Mé'diévale. Turnhout: Brepols, 2006, p. 616. Esta mesma acusação de desinteligência hermenêutica judaica encontra-se expressa no Tratado Theologico ou $O$ Livro das tres creencias: «(...) vos avedes scripto na vossa ley todallas cousas que forom compridas em Jhesu Christo e que vossos prophetas del prophetizarom e o nom entendestes nem ainda entendedes, nem queredes entender, por esso vos diz esto vosso propheta e chama vos poboo sandeu porque nom entendedes a sancta Scriptura e toma della pelo reves e appropriando as sanctas pallavras aas pessoas cujas nom som e que as nom merecem nem comproram em ellas». Cf. José Antunes, A cultura erudita portuguesa nos séculos XIII e XIV (Juristas e Teólogos), p. 730.

57 Mário Martins, «Teatro e Gestas Sagradas», Brotéria, no 44 (1947), p. 553. 
os elementos definidores do teatro medieval ${ }^{58}$. Não deixa, todavia, de admitir o diálogo fecundante que o teatro mantém com as representaçóes parateatrais, a palavra falada com o texto, o teatro religioso com o profano ou o teatro com outros géneros, porque, como bem lembra, «no hay calles de sentido único en la cultura medieval» 59 .

Ora, é inquestionável o efeito dramático que procede da apresentação do litígio sob forma dialogal ${ }^{60}$. Consciente do estatuto performativo que detém e da força perlocutória da sua palavra, a alegoria da Igreja Militante impóe-se no tablado como corpo e voz e é ela que verdadeiramente dinamiza a acção falada de que, na célebre formulação pirandelliana, se faz o teatro. O diálogo na Corte Enperial situa-se, assim, a meio caminho entre a modalidade didáctico-moralizante, pretexto para a contraposição de ideias, e a variante circunstancial-teatral, destinada a atenuar a monorritmia expositiva por meio da apresentação dramática ${ }^{61}$. Assim, se por um lado, são recorrentes marcadores expressivos típicos do dialogismo teatral (como fórmulas de sentido fático - vocativos de coloração afectiva, modalidades de tratamento, indicações deícticas, estratégias de interpelação -, estilemas oralizantes ou procedimentos de cortesia verbal), por outro, parece-me indiscutível que o verdadeiro torneio dialéctico não opõe dramatis personae, mas antes doutrinas corporizadas.

O molde dialogal parece, portanto, uma conveniente máscara retórica para um programa oratório de manifesta vocação injuntiva. A propósito do diálogo castelhano Disputa entre un Judio y un Cristiano, de princípios do século XIII, nota José Miguel

58 Deyermond distingue seis elementos obrigatórios: a mimese, o diálogo, a tensão dramática, o argumento e o texto. Cf. Alan Deyermond, "Teatro, Dramatismo, Literatura: Criterios y Casos Discutibles», in Evangelina Rodríguez Cuadros (coord.), Cultura y representación en la edad media: actas del seminario celebrado con motivo del II Festival de Teatre i Música Medieval d'Elx, octubre-noviembre de 1992. Alicante: Instituto Alicantino Juan Gil-Albert, 1994, pp. 44-45 .

59 Alan Deyermond, «Teatro, Dramatismo, Literatura: Criterios y Casos Discutibles», p. 50.

60 Ana Vian Herrero salienta a estreita relação entre esta componente dramática do diálogo e a sua natureza argumentativa: "Como encuentro mimetizado, realizado en presencia, [o diálogo] añade a menudo otros signos literarios (marco, circunstancias de espacio y tiempo, dramatización de la situación argumentativa, acotaciones implícitas en boca de los interlocutores o en $3^{\text {a }}$ persona del narrador, entradas e salidas de personajes, gestos, tono de las intervenciones, silencios, etc.); todos ellos tienen efecto argumentativo automático, y no pueden ignorarse sin empobrecer, o no interpretar, el sentido cabal del diálogo». Cf. Ana Vian Herrero, «Interlocución y estructura de la argumentación en el diálogo: algunos caminos para una poética del género", Criticón, no 81-82 (2001), p. 148.

${ }^{61}$ Elena Leal Abad, Configuraciones sintácticas y tradiciones textuales. Los diálogos medievales. Sevilla: Universidad de Sevilla, 2008, pp. 252-55. 
Torrejón que "el sermón se disfraza, timidamente, de disputa» ${ }^{62}$. Creio que estas palavras poderiam, sem alterações significativas, ser aplicadas à Corte Enperial. Concedo que os antagonistas são, em última análise, funcionalmente indispensáveis neste diálogo a solo: por um lado, as suas questôes ecoam aquelas que seriam as putativas perplexidades de um adversário real; por outro, catalisam o débito explicativo da rainha católica. Numa espécie de jogo de replicação especular, a disputa textualizada reenvia para um contexto real de missionação. A conversão dos gentios in praesentia destinar-se-ia, neste sentido, tanto a ilustrar os poderes e limites da palavra evangelizadora, como a referendar os resultados desta retórica psicagógica.

No entanto, os encómios estranhamente deslocados que são dirigidos à Igreja Militante permitem suspeitar que se trata, no fim de contas, de um artificioso estratagema de manipulação vocal, que parece às vezes próximo de um verdadeiro exercício de ventriloquismo:

«Raynha senhor, que Deus fez comprida de muito saber», dyse o filosofo gentill, «ora vejo eu que senpre gaanho convosco em vos preguntar, que, posto que as minhas preguntas nom sejam tam neçesarias, senpre as vosas respostas som muy avondosas em grande proveito. E porem ainda quero preguntar se ouvera Deus poder tomar e ajuntar em sy muitas humanidades». (p. 151)

Ora, quando a rainha prescinde das questôes dos interlocutores, não restam dúvidas de que o que realmente se pretende é criar um efeito de mimese conversacional, mais do que reproduzir um efectivo diálogo:

Philosofo amigo, muito sodes trigoso e ainda vos falece muito daquello que vos conpre a saber da muit.alta obra da encarnaçom, hu vos ficou preguntar a maneira como foy feita a encarnaçom. Per ventura pensades que foy naturalmente, asy como som conçibidos e nados outros homẽes, e porem nom curedes mais preguntar, mais eu em toda a guisa vo.llo quero dizer pera o saberdes vós e as gentes que som aqui nestas reaes cortes que esto ainda nom sabem. (p. 153)

62 José Miguel Martínez Torrejón, «Debate y disputa en los siglos XIII y XIV castellanos», in Juan Paredes (ed.), Medioevo y Literatura. Actas del V Congreso de la Asociación Hispánica de Literatura Medieval. Vol. III. Granada: Universidad de Granada, 1995, p. 277. 
De certa maneira, como já foi observado, «os outros grupos presentes são apenas convidados a participar num acto religioso cristão» 63 .

O dispositivo cenográfico onde têm lugar as cortes celestiais indicia o primado da opsis teatral, ao instituir uma dinâmica de ostensão simbolizante que claramente preside à configuração de um espaço cénico hierarquizado em função de um critério sociorreligioso. À semelhança de anotações didascálicas, o discurso com função reificante pode assumir um sentido deíctico, sinalizando a entrada de personagens em cena ${ }^{64}$. Contudo, é aos interlúdios corais que, mais insistentemente, se tem atribuído a exuberante espectaculosidade e o "dramatismo lírico» 65 do texto. Pontuando enfaticamente o triunfo argumentativo da razão cristã ou o júbilo da conversão, os entreactos musicais - constituídos por cânticos entoados pelos membros da corte celestial, sobretudo os anjos e os santos, e, excepcionalmente, pela própria rainha, com acompanhamento instrumental - assinalam um verdadeiro continuum coral, prolongando o árido recitativo da doutrinação. Por outro lado, à semelhança de entremezes, as pausas líricas funcionam como instrumentos de regulação da sintaxe dramática, dividindo os quadros em que pontificam os representantes de cada um dos credos representados. A estes impromptus segue-se, invariavelmente, o silêncio suspensivo e aquiescente de toda a assembleia, precedendo novo contraditório de judeus, mouros e gentios:

Despois que a reynha catolica ouve acabadas suas provas, foy feita grande alegria per toda a real corte. E os angeos começarom a cantar e a tanger muy docemente em seus estormentos, dizendo grandes louvores ao alto Príncipe celestial porque lhe prouguera de se fazer conhecer aos homẽes em algũa maneira. E que, como quer que de todo se nom demostrasse a elles, pero de todo nom se quis encobrir a elles, mais prougue.lhes dar.lhes conhocimento de ssua Triindade. E cantarom logo este cantar: "Gloria à Triindade, hũa igual deviindade ante que todos os segles e agora e

63 Maria Celeste Sousa Silva, Corte Enperial, p. 45.

${ }^{64}$ Cf. por exemplo: «E, cando entrou pello grande canpo hu estava o Celestial Enperador, começou a dizer a outra reinha: "Quem he esta que vem como a manhãa, que se levanta bem fremosa asy como a Lũa, escolheita asy como o Sol, spantosa aos maaos, asy como aaz de ostes bem ordenada?". A esto respondeo ho Enperador Çelestrial: "Esta he a raynha oriental que pasou per o deserto asy como vara muy delguada de fumo d.especias, de mirra e de ençenso e de todalas outras cousas de bõo hodor». (p. 14)

${ }^{65}$ Mário Martins, «A música religiosa na 'Corte Imperial”», p. 420. 
pera senpre, ámen”. E logo os santos que aly estavam responderom, dizendo: "Louvor perduravil e gloria seja a Deus Padre e ao Filho e ao Spiritu Santo per todollos segles dos segres, amen”. E desy calarom.se. (p 98)

Não valerá a pena insistir no modo como o recurso à alegoria, tropo estruturante da obra, se articula, enquanto procedimento substantivante, com este didactismo teatralizado. Angus Fletcher acentua precisamente o facto de a alegoria se inscrever no domínio da retórica epidíctica, onde predominam o elogio e o cerimonial, ajustando-se aos formatos agonísticos da psicomaquia e do debate ideológico ${ }^{66}$. Talvez por isso tenha intuído Mário Martins que «a alegoria das cortes imperiais tem o seu quê duma "moralidade" a que não faltam algumas personificações abstractas» ${ }^{67}$, como, aliás, acontecia com os múltiplas disputas alegóricas medievais que opunham a Igreja e a Sinagoga, indecisas também entre ser literatura polémica ou prefigurar o teatro ${ }^{68}$.

Moralidade sem remate triunfalista ou disputa sem determinatio, a imagem do livro infinito, glosada no explicit da Corte Enprerial, pode bem dever-se ao cansaço do copista, como alvitra Cruz Pontes. Mas não deixa de ser tentador ver neste gesto suspensivo a involuntária figura de um ministério evangelizador perpetuamente inacabado, quando se trata dos «grandes negoçios e os altos feitos e as arduas questôes determinadas» por Deus. 156.

66 Angus Fletcher, Alegoría. Teoría de un modo simbólico. Madrid: Akal., 2002, pp. 122,

${ }^{67}$ Mário Martins, "Corte Imperial», in Alegorias, Simbolos e Exemplos Morais da Literatura Medieval Portuguesa, p. 211.

68 Michel Sleiman, certamente reconhecendo na Corte Enperial uma moralidade rudimentar, acentua que «a descrição dos debatentes e o registro de suas reaçôes psicológicas, o recurso cenográfico dos coros, o uso que eles fazem da palavra cantada e acompanhada por instrumentos musicais, a falta de um juiz a proferir a palavra última, são todos elementos retóricos que se encontrarão ora nos autos de um Gil Vicente, ora nas representações singelas que promoveriam, anos depois, os missionários jesuítas, não sem retomar os pressupostos da prosódia e da métrica vicentinas». Cf. Michel Sleiman, «As reais cortes da Corte enperial», p. 48. 


\section{BIBLIOGRAFIA}

Abad, Elena Leal, Configuraciones sintácticas y tradiciones textuales. Los diálogos medievales. Sevilla: Universidad de Sevilla, 2008.

Antunes, José, A cultura erudita portuguesa nos séculos XIII e XIV (Juristas e Teólogos). Coimbra: Faculdade de Letras, 1995 (dissertação de doutoramento).

Calado, Adelino de Almeida (ed.), Corte Enperial. Aveiro: Universidade de Aveiro, 2000.

Calafate, Pedro (ed.), "O Livro da Corte Imperial», in História do Pensamento Filosófico Português. Lisboa: Caminho, 1999, pp. 533-539.

Campos, Rita de Cássia Boeira, O próximo como o "outro": Cristianismo e Judaísmo na Corte Imperial (Portugal, Século XV). Porto Alegre: UFRGS, 2005 (dissertação de mestrado).

Carter, Henry Hare (ed), Paleographical Edition and Study of the Language of a Portion of Codex Alcobacensis 200. Philadelphia: University of Pennsylvania, 1938.

Carvalho, Mário Santiago de, "Conspecto do desenvolvimento da filosofia em Portugal (séculos XIII-XV)», Revista Española de Filosofia Medieval, no 4 (1997), pp. 131-155.

Costa, Ricardo, «Muçulmanos e Cristãos no diálogo luliano», Anales del Seminario de Historia de la Filosofia (UCM), no 19 (2002), pp. 67-96.

Deyermond, Alan, «Teatro, Dramatismo, Literatura: Criterios y Casos Discutibles», in Evangelina Rodríguez Cuadros (coord.), Cultura y representación en la edad media : actas del seminario celebrado con motivo del II Festival de Teatre i Música Medieval d'Elx, octubre-noviembre de 1992. Alicante: Instituto Alicantino Juan Gil-Albert, 1994, pp. 39-56.

Fletcher, Angus, Alegoría. Teoría de un modo simbólico. Madrid: Akal, 2002.

Fletcher, R., The Barbarian Conversion. From Paganism to Christianity. Berkeley: University of California Press, 1999.

Ganho, Maria de Lourdes S., "A perspectiva ética na obra anónima 'Corte Enperial'», in Marcos Roberto N. Costa e Luis A. de Boni (orgs.), A Ética Medieval Face aos Desafios da Contemporaneidade. Porto Alegre: EPIPUCRS, 2004, pp. 663-678.

Lasker, Daniel J., «Imagination and Intellect in the Medieval Jewish Philosophical Polemics against Christianity», in Maria Cândida Pacheco e José F. Meirinhos (eds.), Intellect et Imagination dans la Philosophie Médiévale. Turnhout: Brepols, 2006, pp. 616-624.

Leclercq, Jean, Initiation aux auteurs monastiques du Moyen Âge. L'amour des lettres \& le désir de Dieu. Paris: Les Éditions du Cerf, 1956.

Martínez Torrejón, José Miguel, «Debate y disputa en los siglos XIII y XIV castellanos», in Juan Paredes (ed.), Medioevo y Literatura. Actas del V Congreso de la Asociación Hispánica de Literatura Medieval. Vol. III. Granada: Universidad de Granada, 1995, pp. 275-286.

Martins, Mário, "A polémica religiosa nalguns códices de Alcobaça», Brotéria, no 42 (1946), pp. 241-250.

— «Teatro e Gestas Sagradas», Brotéria, no 44 (1947), pp. 543-53. 
— «Visionarismo literário de quatrocentos», Brotéria, no 47 (1948), pp. 19-35.

— «O 'Diálogo de Robim e do Teólogo'», Brotéria, no 53 (1951), pp. 271-276.

— «A música religiosa na 'Corte Imperial'», in Estudos de Literatura Medieval. Braga: Livraria Cruz, 1956, pp. 417-421.

— «Sabiúda, a 'Corte Imperial' e o racionalismo naturalista», in Estudos de Literatura Medieval. Braga: Livraria Cruz, 1956, pp. 395-415.

— "O Livro da Corte Imperial», in As Grandes Polémicas Portuguesas. Lisboa: Verbo, 1964, pp. 29-49.

- Introdução histórica à vidência do tempo e da morte. Braga: Livraria Cruz., 1969.

— «Corte Imperial», in Alegorias, Simbolos e Exemplos Morais da Literatura Medieval Portuguesa. Lisboa: Edições Brotéria, 1980, pp. 207-212.

Menocal, María Rosa, The Ornament of the World: How Muslims, Jews and Christians Created a Culture of Tolerance in Medieval Spain. Boston: Little, Brown \& Company, 2002.

Pacheco, Maria Cândida Monteiro, "Corte Imperial», in Giulia Lanciani e Giuseppe Tavani (orgs.), Dicionário da Literatura Medieval Galega e Portuguesa. Lisboa: Caminho, 1993, pp. 169-70.

Perelman, Chaïm e Olbrechts-Tyteca, Lucie, Tratado da Argumentação. Lisboa: Instituto Piaget, 2006.

Pontes, J. M. da Cruz, «Originalidade literária da Corte Enperial», Diário Ilustrado, 2 de Março de 1957.

— «Teatralidade da Corte Enperial», Diário Ilustrado, 7 de Maio de 1957.

- Estudo para uma edição crítica da Corte Enperial. Coimbra: Universidade de Coimbra, 1957.

— «Raimundo Lulo, o Colégio de Miramar e Portugal», Itinerarium, no 96-97 (1977), pp. 195-211.

— «Corte Enperial (Livro da)», in Biblos. Enciclopédia Verbo das Literaturas de Língua Portuguesa. Vol. 1. Lisboa: Verbo, 1995, pp. 1307-1310.

— «Raimundo Lulo - na polémica medieval religiosa do 'Livro da Corte Imperial'», in Ernildo Stein (org.), A Cidade de Deus e a Cidade dos Homens de Agostinho a Vico. Festschrift para Luis Alberto de Boni. Porto Alegre: EDIPUCRS, 2004, pp. 681-695.

- «Apostilas para a edição crítica do Livro da Corte Enperial», Humanitas, no 58 (2006), pp. 229-252.

Reboul, Olivier, Introdução à Retórica. São Paulo: Martins Fontes, 1998.

Sanmartín Bastida, Rebeca, Teatralidad y Textualidad en el Arcipreste de Talavera. London: Queen Mary, University of London/Department of Hispanic Studies (Papers of the Medieval Hispanic Research Seminar), 2003.

Saraiva, António José, O crepúsculo da Idade Média em Portugal. Lisboa: Gradiva, 1998. 
Serverat, Vincet, L'Être et la Joie. La philosophie de Ramon Llull dans le "Le Libre d'amic e amat». Greifswald: Reineke-Verlag, 1993.

Sidarius, Adel, «Le Livro da Corte Enperial entre l'apologétique lulienne et l'expansion catalane au XIVe siècle», in Horacio Santiago-Otero (ed.), Diálogo Filosófico-Religioso entre Cristianismo, Judaísmo e Islamismo durante la Edad Media en la Peninsula Ibérica. Turnhout: Brepols, 1994, pp. 131-172.

Silva, Maria Celeste Sousa, Corte Enperial. Porto: Faculdade de Letras, 2005 (dissertação de mestrado).

Sleiman, Michel, «As reais cortes da Corte enperial», in Lênia Márcia de Medeiros Mongelli (coord.), A Literatura Doutrinária na Corte de Avis. São Paulo: Martins Fontes, 2001, pp. 3-49.

— «Fé, razão e diferenças na Corte enperial», in Ângela Vaz Leão e Vanda de Oliveira Bittencourt (orgs.), Anais do IV Encontro Internacional de Estudos Medievais. Belo Horizonte: PUC Minas, 2003, pp. 667-673.

Tavares, Maria José Ferro, «A construção de um estereótipo: o judeu no Mediterrâneo ocidental e o seu reflexo na arte (séculos XII a XVI)», in Maria Filomena Lopes de Barros e José Hinojosa Montalvo (eds.), Minorias étnico-religiosas na Peninsula Ibérica. Periodos medieval e moderno. Actas: I Encontro Minorias no Mediterrâneo, Évora, 21-23 de Setembro de 2006. Lisboa: Colibri-CIDEHUS, 2008, pp. 17-78.

Vian Herrero, Ana, «Interlocución y estructura de la argumentación en el diálogo: algunos caminos para una poética del género", Criticón, no 81-82 (2001), pp. 157-190.

— «Voces áureas. La prosa. Problemas terminológicos y cuestiones de concepto», Criticón, no 81-82 (2001), pp. 143-155. 